\title{
Awareness and practice of emergency contraception at a private university in Nigeria
}

\author{
Jacob Olumuyiwa Awoleke1, Abiodun Idowu Adanikin 1*, Adeola Awoleke ${ }^{2}$ and Moyinoluwa Odanye ${ }^{2}$
}

\begin{abstract}
Background: The pursuit of formal education now causes many people in developing countries to marry later in life, thereby leading to increased premarital sex and unintended pregnancies. Efforts have been made to characterize awareness and use of emergency contraception (EC) among undergraduate students in public universities in Nigeria; however, it is not known if students in private tertiary institutions adopt different practices or if having an affluent family background plays a role. This pilot study therefore aimed to assess the awareness and use of EC among students at a private Nigerian university toward assisting education planners in developing strategies in improving students' reproductive well-being.

Results: Out of 94 female students, 42 (44.7\%) had sexual experience, but only 32 (34.0\%) were currently sexually active. Six students (6.4\%) had had unwanted pregnancies, of which all but one were terminated. Fifty-seven respondents (60.6\%) were aware of EC, though only $10(10.6 \%)$ ever practiced it. The greatest source of EC information was from health workers and peers; the lowest source was family or relatives. Most respondents desired orientation and availability of EC on campus. EC awareness among the students was predicted by upper social class background (adjusted odds ratio [OR], 2.73; 95\% confidence interval [CI], 1.06-7.45) and upbringing in the Federal Capital Territory (adjusted OR, 4.45; 95\% Cl, 1.56-14.22).

Conclusions: Though awareness of EC was higher among the private university students in this study than at most public universities, there was no difference in EC usage. A high pregnancy termination rate was observed; dilatation and curettage were mainly adopted. In Nigeria, youth-friendly reproductive health information and access should not be limited to government-owned tertiary institutions but also extended to private ones.
\end{abstract}

Keywords: Africa, Student, Undergraduate, Private university, Emergency contraception

\section{Background}

Emergency contraception (EC) refers to a group of birth control modalities that when used after unprotected intercourse within defined time limits can prevent an unwanted pregnancy [1]. Unlike regular methods of contraception adopted before sexual intercourse, EC is used to avoid pregnancy after unprotected sex. It therefore has a last-resort potential of avoiding unwanted pregnancy and, by extension, unsafe abortion, which is a desirable goal-especially in countries where abortion is illegal [2]. Research has shown that EC is largely underutilized

\footnotetext{
*Correspondence: adanikinbiodun@yahoo.com

${ }^{1}$ Department of Obstetrics and Gynaecology, Ekiti State University

Teaching Hospital, Ado-Ekiti, Nigeria

Full list of author information is available at the end of the article
}

worldwide, and it has been referred to as one of the bestkept secrets in reproductive health [3].

Approximately 6.8 million pregnancies occur annually in Nigeria; the majority of these pregnancies are unplanned and usually unwanted [4]. More than 610,000 induced abortions occur annually in the country, and young people are responsible for over $60 \%$ of them [5]. When pregnancies are unwanted and unplanned in many low-income countries, they have a negative impact on the reproductive health of young adults since some of them resort to unsafe abortions, which are often complicated by genital infections, infertility, permanent morbidities, and sometimes death [2, 5-7].

About $44 \%$ of the Nigerian population consists of young people [8]. In contrast to previous practice, many Nigerians are now marrying later because of longer 
formal education, and they are increasingly engaging in premarital sex [9]. Therefore, the need for EC has grown in this category of individuals, who engage in sporadic, erratic, casual sexual intercourse, since EC offers a valuable means of preventing pregnancy [2]. Depending on the method used, EC can reduce the risk of becoming pregnant from a single act of sexual intercourse by $75-99 \%$ [10].

Some studies have examined the awareness and practice of EC among undergraduate students in Nigeria, but none has considered its practice among private university students. Privatization of the university system is a relatively recent development in this country. Because of the exorbitant fees, the majority of students attending private universities are from the upper socioeconomic class, who may be better informed about EC. Another consideration is that although their social background may assist in enhancing their academic progress, their younger age within the university system could make them vulnerable to more sexual experimentation. The present study aimed to survey sexual practices, EC awareness, and EC use in Nigerian private university students. We believed that the results would shed light on some gray areas in EC practices and assist education planners in crafting strategies toward improving students' reproductive well-being.

\section{Methods}

This pilot cross-sectional study about EC awareness and practices among female undergraduates at a private university was conducted in southwest Nigeria between July and August 2013. The Ethics Committee of Ekiti State University Teaching Hospital, Ado-Ekiti, Nigeria reviewed the study protocol and gave its approval. Study permission was also obtained from the authority of the private university in question, though it requested its name not be mentioned.

The primary outcome of interest was the use of EC among the students. We employed a previous report about the overall prevalence of EC being 6\% (30/500) among undergraduates in Nigeria to calculate the minimum sample size required [11]. We determined that at least 87 participants would be needed for a standard normal deviation of 1.96 at the $95 \%$ confidence level with an error margin of 0.05 . We administered 100 questionnaires to allow for non-response.

The private university studied has six faculties: law; engineering; medicine and health sciences; social and management studies; social justice; and natural and applied sciences. We used a multistage sampling approach to select the respondents. We first chose two of the faculties (engineering; social and management sciences) by balloting. We then selected two departments from each of those faculties also by balloting. They were the departments of Civil and Mechanical Engineering from the Faculty of Engineering and the departments of Psychology and Economics from the Faculty of Social and Management Sciences. We subsequently used a simple random sampling technique in administering 25 questionnaires to female students in each of the four departments.

Before conducting the study, we pre-tested a semistructured questionnaire at the Federal Polytechnic, Ado-Ekiti, which is a government tertiary institution in the same locality, using ten respondents. We did this to assess the ambiguity and comprehensibility of the study instrument. We subsequently modified any ambiguous questions for ease of comprehension.

After obtaining informed written consent from the participants, the questionnaires were distributed to them by hand. Respondents were given time to complete the questionnaires, which were retrieved the same day to avoid losses. The net response rate was $94 \%$, and we based our analysis on that.

The data obtained were structured with respect to the sociodemographic characteristics of the respondents, and they included the following: age; religion; social class of the parents; place of upbringing; relationship status; year of study at the institution; sexual practices; occurrence of unwanted pregnancy and its outcome; awareness and practice of EC; and desire for EC education in the school's orientation program. The collected data were entered into SPSS package version 17 [SPSS Inc., Chicago, USA] and analyzed. The results were expressed as simple percentages, and logistic regression analysis was employed as appropriate. We set the level of significance $(\alpha)$ at 0.05 .

\section{Results}

Table 1 shows the sociodemographic characteristics of the students. Only two (2.1\%) were married; 11 (11.7\%) cohabited with their boyfriends during holidays; the others were single. The majority - 71 students (75.6\%) - were from families in the upper social strata (Social Class I and II); 57 (60.6\%) were originally from southwestern Nigeria.

With respect to sexual practices, 42 (44.7\%) had sexual experience (Table 2). Among those sexually exposed, 33 (78.6\%) had their sexual debut at or before the age of 22 years; 27 respondents (64.3\%) with sexual experience used contraceptive protection. In the sampled population, 32 respondents (34.0\%) were currently sexually active (had had sex within the previous 6 months), and six $(6.4 \%)$ had had an unwanted pregnancy, though only one $(16.7 \%)$ resulted in birth. The most practiced form of pregnancy termination was dilatation and curettage.

Table 3 presents the knowledge and practice of EC among the respondents. Over half of the respondents -57 
Table 1 Sociodemographic characteristics of respondents

\begin{tabular}{lcc}
\hline Variables & Frequency (\%) & Range \\
\hline Age (years) & & \\
$\leq 22$ & $69(73.4)$ & \\
$\geq 23$ & $25(26.6)$ & \\
Religion & & \\
Christianity & $80(85.1)$ & \\
Islam & $14(14.8)$ \\
Family social class & \\
Class I & $31(33.0)$ \\
Class II & $40(42.6)$ \\
Class III & $14(14.9)$ \\
Class IV & $9(9.5)$ \\
Class V & $0(0)$ \\
Place of childhood upbringing (Nigerian region) \\
Southwest & $57(60.6)$ \\
Southeast & $4(4.3)$ \\
South-south & $8(8.5)$ \\
Northeast & $2(2.1)$ \\
Northwest & $3(3.2)$ \\
North central & $2(2.1)$ \\
FCT & $18(19.2)$ \\
Relationship status & \\
Single & $81(86.1)$ \\
Cohabits with boyfriend & $11(11.7)$ \\
Married & $2(2.1)$ \\
Year of study & \\
1st year & $11(7.4)$ \\
2nd year & $23(24.5)$ \\
3rd year & $36(38.3)$ \\
4th year & $17(18.1)$ \\
\hline
\end{tabular}

(60.6\%)-were aware of EC, but only 10 (10.6\%) ever practiced it. With regard to sources of information, peers and health workers ranked highest; the lowest source was family or relatives. The levonorgestrel EC pill (Postinor) was the most commonly adopted method (seven respondents; 70.0\%), followed by Menstrogen (two; 20.0\%), and intrauterine contraceptive device (one; $10.0 \%)$. Twelve respondents $(21.0 \%)$ believed that EC was effective before sex; 13 (22.8\%) had no knowledge of the period of its effectiveness. Twenty students (35.1\%) understood that its effectiveness was confined to within $24 \mathrm{~h}$ after intercourse, whereas 11 respondents (19.3\%) declared that it was still effective until $72 \mathrm{~h}$ after sex. Just one student believed that it could be used up to 5 days post-intercourse.

Most respondents (55 students; $58.5 \%$ ) desired EC orientation on campus; 48 students (51.1\%) wanted EC to be available on campus. Forty-four students (46.8\%) stated
Table 2 Sexual practices of respondents

\begin{tabular}{lc}
\hline Variable & Frequency (\%) \\
\hline Ever had sex, $n=94$ & $42(44.7)$ \\
Yes & $52(55.3)$ \\
No & \\
Age at sexual debut (years), $n=42$ & $33(78.6)$ \\
$\leq 22$ & $9(21.4)$ \\
$\geq 23$ & \\
Was exposure protected?, $n=42$ & $27(64.3)$ \\
Yes & $15(35.7)$ \\
No & \\
Presently sexual active?, $n=94$ & $32(34.0)$ \\
Yes & $62(66.0)$ \\
No & \\
Had unwanted pregnancy?, $n=94$ & $6(6.4)$ \\
Yes & $88(93.6)$ \\
No & \\
Outcome of unwanted pregnancy, $n=6$ & $1(16.7)$ \\
Delivered & $5(83.3)$ \\
Aborted & \\
Abortion method, $n=5$ & $2(40.0)$ \\
Medical & $3(60.0)$ \\
D\&C &
\end{tabular}

that they would use EC in future. Our regression model showed that being from an upper social class (adjusted odds ratio [OR], 2.73; 95\% confidence interval [CI], 1.067.45) and having an upbringing in the Federal Capital Territory (adjusted OR, 4.45; 95\% CI, 1.56-14.22) predicted EC awareness among the students (Table 4).

\section{Discussion}

Unlike most previous studies, which considered subjects in government-owned institutions, the present investigation examined the awareness and practice of $\mathrm{EC}$ in a private tertiary institution in Nigeria. We found close to half of our respondents had had sexual intercourse, and a third were currently sexually active. The awareness of EC was above average among the students, but its practice was low. Consequently, unwanted pregnancies occurred, almost all of which were terminated.

When compared with sexual practices of female students in government-owned tertiary institutions in Nigeria, the proportion $(44.7 \%)$ of respondents with sexual experience in the present study was close to the $48.2 \%$ reported for the University of Ibadan but significantly lower than the $85.3 \%$ of the University of Portharcourt $[12,13]$. In our study, the proportion $(34.0 \%)$ of students who were currently sexually active was also less than the $43 \%$ observed at the University of Benin and the $56.1 \%$ at the University of Lagos $[5,14]$. This observation 
Table 3 Knowledge and practice of emergency contraception (EC) among respondents

\begin{tabular}{|c|c|}
\hline Variable & Frequency (\%) \\
\hline \multicolumn{2}{|l|}{ Aware of $E C, n=94$} \\
\hline Yes & $57(60.6)$ \\
\hline No & $37(39.4)$ \\
\hline \multicolumn{2}{|c|}{ Source of EC knowledge, $n=57$} \\
\hline Media & $12(21.0)$ \\
\hline Friends/peers & $14(24.6)$ \\
\hline Health worker & $17(29.8)$ \\
\hline Family/relatives & $1(1.8)$ \\
\hline Books/magazine & $9(15.8)$ \\
\hline Campaign outreaches & $4(7.0)$ \\
\hline \multicolumn{2}{|l|}{ Ever used EC, $n=94$} \\
\hline Yes & $10(10.6)$ \\
\hline No & $84(89.4)$ \\
\hline \multicolumn{2}{|l|}{ Type of EC used, $n=10$} \\
\hline LNG pill (Postinor) & $7(70.0)$ \\
\hline Menstrogen & $2(20.0)$ \\
\hline IUCD & $1(10.0)$ \\
\hline \multicolumn{2}{|c|}{ Source of EC procurement, $n=10$} \\
\hline Public hospital & $1(10.0)$ \\
\hline Private hospital & $4(40.0)$ \\
\hline Pharmacy/chemist & $5(50.0)$ \\
\hline \multicolumn{2}{|c|}{ When is EC effective?, $n=57$} \\
\hline Before sex & $12(21.0)$ \\
\hline Within $24 \mathrm{~h}$ after sex & $20(35.1)$ \\
\hline Within $72 \mathrm{~h}$ after sex & $11(19.3)$ \\
\hline Up to 5 days after sex & $1(1.8)$ \\
\hline Don't know & $13(22.8)$ \\
\hline \multicolumn{2}{|c|}{ Perceived side effect of EC, $n=57$} \\
\hline Nausea and vomiting & $4(7.0)$ \\
\hline Weight gain & $7(12.3)$ \\
\hline Menstrual irregularities & $17(29.8)$ \\
\hline Infertility & $16(28.1)$ \\
\hline Bleeding disturbances & $4(7.0)$ \\
\hline Not known & $9(15.8)$ \\
\hline \multicolumn{2}{|c|}{ Desire EC orientation on campus, $n=94$} \\
\hline Yes & $55(58.5)$ \\
\hline No & $23(24.5)$ \\
\hline No response & $16(17.0)$ \\
\hline \multicolumn{2}{|c|}{ Desire EC is available on campus, $n=94$} \\
\hline Yes & $48(51.1)$ \\
\hline No & $30(31.9)$ \\
\hline No response & $16(17.0)$ \\
\hline \multicolumn{2}{|l|}{ Will use EC in future, $n=94$} \\
\hline Yes & $44(46.8)$ \\
\hline No & $30(31.9)$ \\
\hline No response & $20(21.3)$ \\
\hline
\end{tabular}

LNG levonorgestrel.
Table 4 Regression analysis of predictors of emergency contraception (EC) awareness

\begin{tabular}{|c|c|c|c|c|c|}
\hline \multirow[t]{2}{*}{ Variable } & \multicolumn{2}{|c|}{ EC awareness $n$ (\%) } & \multirow{2}{*}{$\begin{array}{l}\text { Total } \\
n(\%)\end{array}$} & \multirow{2}{*}{$\begin{array}{l}\text { Adjusted } \\
\text { odd ratio }\end{array}$} & \multirow[t]{2}{*}{$95 \% \mathrm{Cl}$} \\
\hline & Yes & No & & & \\
\hline \multicolumn{6}{|l|}{ Age (years) } \\
\hline$\leq 22$ & $38(55.1)$ & $31(44.9)$ & $69(100)$ & 1.00 & \\
\hline$\geq 23$ & $19(76.0)$ & $6(24.0)$ & $25(100)$ & 0.41 & $0.14-1.07$ \\
\hline \multicolumn{6}{|l|}{ Religion } \\
\hline Christianity & $50(62.5)$ & $30(37.5)$ & $80(100)$ & 1.00 & \\
\hline Islam & $7(50.0)$ & $7(50.0)$ & $14(100)$ & 1.66 & $0.55-5.03$ \\
\hline \multicolumn{6}{|l|}{ Social class } \\
\hline 1 & $15(48.4)$ & $16(51.6)$ & $31(100)$ & 2.73 & $1.06-7.45^{*}$ \\
\hline$\|$ & $29(72.5)$ & $11(27.5)$ & $40(100)$ & 1.00 & \\
\hline III & $6(42.9)$ & $8(57.1)$ & $14(100)$ & 3.35 & $1.03-12.01^{*}$ \\
\hline IV & $7(77.8)$ & $2(22.2)$ & $9(100)$ & 0.86 & $0.15-3.85$ \\
\hline \multicolumn{6}{|c|}{ Place of childhood upbringing } \\
\hline Southwest & $40(70.2)$ & $17(29.8)$ & $57(100)$ & 1.00 & \\
\hline Southeast & $4(100)$ & $0(0)$ & $4(100)$ & 0.26 & $0.02-3.72$ \\
\hline Southsouth & $3(37.5)$ & $5(62.5)$ & $8(100)$ & 3.64 & $0.92-16.76$ \\
\hline Northcentral & $0(0)$ & $2(100)$ & $2(100)$ & 11.57 & $0.32-1.00$ \\
\hline Northeast & $2(100)$ & $0(0)$ & $2(100)$ & 0.46 & $0.01-13.31$ \\
\hline Northwest & $2(66.7)$ & $1(33.3)$ & $3(100)$ & 1.39 & $0.15-9.04$ \\
\hline $\mathrm{FCT}$ & $6(33.3)$ & $12(66.7)$ & $18(100)$ & 4.45 & $1.56-14.22^{*}$ \\
\hline \multicolumn{6}{|c|}{ Relationship status } \\
\hline Single & $47(58.0)$ & $34(42.0)$ & $81(100)$ & 1.00 & \\
\hline $\begin{array}{c}\text { Cohabit with } \\
\text { boyfriend }\end{array}$ & $8(72.7)$ & $3(27.3)$ & $11(100)$ & 0.57 & $0.14-1.98$ \\
\hline Married & $2(100)$ & $0(0)$ & $2(100)$ & 0.28 & $0.01-7.68$ \\
\hline \multicolumn{6}{|l|}{ Year of study } \\
\hline 1st year & $2(28.6)$ & $5(71.4)$ & $7(100)$ & 5.55 & $0.85-74.96$ \\
\hline 2nd year & $13(56.5)$ & $10(43.5)$ & $23(100)$ & 1.96 & $0.68-5.89$ \\
\hline $3 r d$ year & $26(72.2)$ & $10(27.8)$ & $36(100)$ & 1.00 & \\
\hline 4th year & $10(58.8)$ & $7(41.2)$ & $17(100)$ & 1.80 & $0.56-5.93$ \\
\hline 5th year & $6(54.5)$ & $5(45.5)$ & $11(100)$ & 2.14 & $0.57-8.28$ \\
\hline
\end{tabular}

* Statistically significant.

controverts the assumed likelihood of more sexual experimentation among these "privileged" students.

Our finding of $60.6 \%$ EC awareness among the private university students is similar to the value reported for public institutions in Lagos and Benin, Nigeria where 58 and $67.8 \%$ of female students had heard of EC $[5,14]$. It is, however, higher than the awareness of $24.3,38.1$, and $46 \%$, respectively, from public universities in the Nigerian states of Oyo, Anambra, and Ebonyi [11, 12, 15]. A comparison with other African universities shows that EC awareness is higher than the $51.4 \%$ reported for Ghana and $45.1 \%$ for Uganda [16, 17], though it is much lower than the 95\% reported for Princeton University and Mexico [18, 19]. 
The practice of EC by the students in the present study showed no remarkable departure from observations in public tertiary institutions in Nigeria [11, 12, 15]. Unlike in those public universities, the private students mostly obtained EC awareness from health workers and then from peers. It is likely that the high socioeconomic background of our respondents offered them access to health facilities and personnel, which provided reproductive health services. Further, being from an upper social class and having an upbringing in the Federal Capital Territory led to increased EC awareness.

We found that $20 \%$ of respondents erroneously used Menstrogen as EC. Only a fifth of students knew the correct timing of EC usage. This is in line with reports from sister public universities [14, 20]. It is possible that distorted information about EC was obtained from such sources as peers and magazines or other media. This finding points to the need for greater education on reproductive health in general and EC in particular. Specifically, establishing youth-friendly reproductive health centers at each university would be an appropriate move.

Owing to its attendant complications, the dominance of pregnancy termination by dilatation and curettage indicates both a short- and long-term danger for the students in this study. In an environment where abortion is not legalized, a more sensible precautionary measure would be to increase EC awareness among young people. This need certainly exists, as evidenced by more than half of our respondents wanting campus orientation about EC and EC availability on campus.

One strength of the present investigation is its pilot nature: no previous study in Nigeria has examined EC usage at a private university. The small sample size could limit the generalizability of our results; however, the fact that the sample size was calculated using a standard formula and sampling bias was minimized gives the study robustness and reproducibility. We recognized from the outset that the subject of our research was unlikely to receive ready acceptance by the authorities of most private educational institutions, which are intent on preserving their moral reputation.

\section{Conclusions}

Contrary to expectations, we found the prevalence of sexual activity among private university female students to be slightly lower than that of their counterparts in public universities in Nigeria. Higher socioeconomic background and place of childhood upbringing were found to be predictors of EC awareness. However, we observed that the actual use of EC did not differ from that among other female students in public tertiary institutions. The very high pregnancy termination rate of $84 \%$ among those who became pregnant underlines the need for effective contraceptive education on campuses; it is necessary as a preventive measure in a society where abortion is illegal and unsafe termination through dilatation and curettage still dominates. We also recognize that educating young people about safer pregnancy termination methods may be needful, though Nigeria's current restrictive abortion laws present a stumbling block. It is necessary to make concerted efforts to promote youthfriendly reproductive health services and rights at both public and private institutions.

\section{Abbreviation}

EC: emergency contraception.

\section{Authors' contributions}

$\mathrm{AJO}$ and $\mathrm{AAl}$ designed the study; $\mathrm{AA}$ and OM conducted the study; analysis of data was undertaken by AAI. All the authors contributed to the intellectual content of the manuscript. All authors read and approved the final manuscript.

\section{Author details}

${ }_{1}^{1}$ Department of Obstetrics and Gynaecology, Ekiti State University Teaching Hospital, Ado-Ekiti, Nigeria. ${ }^{2}$ School of Nursing and Midwifery, Ekiti State University Teaching Hospital, Ado-Ekiti, Nigeria.

Acknowledgements

None.

\section{Compliance with ethical guidelines}

\section{Competing interests}

The authors declare that they have no competing interests.

Received: 16 March 2015 Accepted: 7 May 2015

Published online: 04 June 2015

\section{References}

1. Jamieson MA, Hertweck SP, Sanfilippo JS (1999) Emergency contraception: lack of awareness among patients presenting for pregnancy termination. J Pediatr Adolesc Gynecol 12(1):11-15

2. Kongnyuy EJ, Ngassa P, Fomulu N, Wiysonge CS, Kouam L, Doh AS (2007) A survey of knowledge, attitudes and practice of emergency contraception among university students in Cameroon. BMC Emerg Med 7:7

3. Gemzell-Danielsson K, Marions L (2004) Mechanisms of action of mifepristone and levonorgestrel when used for emergency contraception. Hum Reprod Update 10(4):341-348

4. Ameha H, Nebreed F (2006) Emergency contraception: potential clients and providers perspectives. Ethiop J Health Sci 16(1):2-5

5. Ebuehi OM, Ekanem EE, Ebuehi OAT (2006) Knowledge and practice of emergency contraception among female undergraduates in the University of Lagos, Nigeria. East Afr Med J 83(3):90-95

6. Cheng L, Gulzmezoglu AM, Oel CJ, Piaggio G, Ezcurra E, Look PF (2004) Interventions for emergency contraception. Cochrane Database Syst Rev 3:CD001324

7. Etalemahu D Assessment of barriers of emergency contraception use among antenatal care clients of Addis Ababa health centers. Addis Ababa University Libraries Electronic Thesis and Dissertations: AAU-ETD, Faculty of medicine: Thesis-public health 2007. http://etd.aau.edu.et/dspace/ handle/123456789/817. Accessed 20 Sept 2014

8. Chowdhury S Draft for discussion: Health Nutrition and Population (HNP) World Bank; 2009. The World Bank's Reproductive Health Action Plan 2010-2015. http://siteresources.worldbank.org/INTPRH/ 
Resources/376374-1261312056980/120109RHAPPresentation.pdf. Accessed 30 Aug 2014

9. Bankole A, Oye-Adeniran BA, Singh S, Adewole IF, Wulf D, Sedgh G et al Unwanted pregnancy and induced abortion in Nigeria: causes and consequences. http://www.guttmacher.org/pubs/2006/08/08/Nigeria-UP-IA. pdf. Accessed 18 Sept 2014

10. Adhikari R (2009) Factors affecting awareness of emergency contraception among college students in Kathmandu, Nepal. BMC Womens Health 9:27

11. Ibekwe PC, Obuna JA (2010) Awareness and practice of emergency contraception among university students in Abakaliki, southeast Nigeria. Niger J Clin Pract 13(1):20-23

12. Bello FA, Olayemi O, Fawole AO, Ogunbode OO, Sobukunola T, Adesina OA et al (2009) Perception and practice of emergency contraception among female undergraduates of the University of Ibadan, Nigeria. J Reprod Contracept 20(2):113-121

13. Akani Cl, Enyindah CE, Babatunde S (2008) Emergency contraception: knowledge and perception of female undergraduates in the Niger Delta of Nigeria. Ghana Med J 42(2):68-70

14. Aziken ME, Okonta PI, Ande ABA (2003) Knowledge and perception of emergency contraception among female Nigerian undergraduates. Int Fam Plan Perspect 29(2):84-87
15. Nworah JAO, Sunday UM, Joseph OU, Monday OO, Josephat AC (2010) Knowledge, attitude and practice of emergency contraception among students in tertiary schools in Anambra State Southeast Nigeria. Int J Med Med Sci 2(1):1-4

16. Addo VN, Tagoe-Darko ED (2009) Knowledge, practices and attitudes regarding emergency contraception among students at a University in Ghana. Int J Gynecol Obstet 105:206-209

17. Byamugisha JK, Mirembe FM, Faxelid E, Gemzell-Danielsson K (2006) Emergency contraception and fertility awareness among university students in Kampala, Uganda. Afr Health Sci 6(4):194-200

18. Harper CC, Ellertson CE (1995) The emergency contraceptive pill: a survey of knowledge and attitudes among students at Princeton University. Am J Obstet Gynecol 173(5):1438-1445

19. Tapia-Curiel A, Villasenor-Farias M, Nuno-Gutierrez BL (2008) Knowledge and attitudes about using emergency contraceptives among young college students. Rev Med Inst Mex Seguro Soc 46(1):33-41

20. Adeniji AO, Tijani AM, Owonikoko KM (2013) Knowledge and determinants of emergency contraception use among students in tertiary institution in Osun State, Nigeria. J Basic Clin Reprod Sci 2(1):46-53

\section{Submit your next manuscript to BioMed Central and take full advantage of:}

- Convenient online submission

- Thorough peer review

- No space constraints or color figure charges

- Immediate publication on acceptance

- Inclusion in PubMed, CAS, Scopus and Google Scholar

- Research which is freely available for redistribution

Submit your manuscript at

www.biomedcentral.com/submit

() Biomed Central 